\title{
Entrustable Professional Activities: A Primer for Canadian Pharmacy Preceptors
}

Kerry Wilbur

\section{INTRODUCTION}

$\mathrm{T}$ rust is the fundamental fabric of pharmacy. Pharmacists are consistently voted the most trusted group of professionals by Canadians and are highly rated on their reliability and honesty in surveys conducted each year elsewhere around the world. ${ }^{1-4}$ Our abilities to develop and maintain collaborative relationships with patients, our knowledge of how to manage minor ailments or make appropriate referrals for further care and support, and our participation in health and wellness promotion are just some of the characteristics that instill the public's confidence in pharmacists. ${ }^{5}$

Guidance for instructing pharmacy students in these and other expected pharmacist competencies is outlined in the educational outcomes of the Association of Faculties of Pharmacy of Canada (AFPC). ${ }^{6}$ Students are enrolled in campus-based curricula designed to develop medication therapy experts, complemented by at least 16 or 40 weeks of experiential training for Bachelor of Science in Pharmacy and entry-to-practice Doctor of Pharmacy (PharmD) programs, respectively, of which 12 weeks (Bachelor's) or 24 weeks (PharmD) is full time at pharmacy practice sites. ${ }^{7}$ Under this apprenticeship model, students reinforce and shape their development of existing knowledge, skills, and attitudes while engaged in patient care. ${ }^{8}$ Workplace-based activities further students' abilities to assume their role as medication therapy experts through practice and demonstration of the key competencies outlined by AFPC roles: care provider, communicator, collaborator, leader-manager, health advocate, scholar, and professional.

Pharmacists throughout the country, including those in hospitals and other inpatient settings, supervise students in their practice. The educational faculties additionally ask these practitioners to offer assessments of student performance, which inform program decisions about students' developing abilities and, ultimately, their suitability for graduation and application for licensure. However, problems are evident in workplace-based assessments of competency-based health professional programs such as pharmacy. Clinical supervisors are not necessarily able to relate specified educational outcomes to observed workplace functions. Indeed, patient care is complex and not easily distilled into isolated competencies for independent assessment. For example, how does a pharmacy preceptor grade a student who has conducted a technically sound medication history (medication expert outcome) but who lacked empathy during the patient encounter (communicator outcome)? Furthermore, studies in pharmacy, medicine, and social work have shown that preceptors value student attributes that are not readily outlined on evaluation forms. ${ }^{9-11}$ Indeed, measurement of "motivation", "energy", and "personality" is elusive. A preceptor's impressions, or "gut feeling", about a student's capabilities to fulfill patient care roles may also be less easily expressed. ${ }^{12}$

\section{ASSESSING THE COMPETENCIES OF HEALTH PROFESSIONAL STUDENTS}

In an effort to reconcile incongruity between actual workplace-based student care activities and the competencies that educational programs expect for learner assessment, Dutch medical educators put forth a complementary educational concept of "entrustable professional activities" (EPAs). ${ }^{13}$ The premise of this concept is that the competencies possessed by a health professional trainee must be those applied in clinical contexts. An EPA has been defined as "a unit of professional practice" that, according to the opinion of leaders in the respective health professional field, must be assessed and approved during training. ${ }^{14}$ An EPA is therefore a discrete collection of tasks that a clinical supervisor entrusts to a student with unsupervised responsibility once the student has demonstrated the necessary competence. As an example from the EPApioneering specialty of obstetrics and gynecology in the Netherlands, medical residents are expected to manage uncomplicated antenatal care (EPA 1.1 in the program's competency-based 
curriculum $^{15}$ ), an overarching EPA that outlines distinct target experiences such as provision of preconception advice, assessment of feasibility of induction of labour, and ability to conduct basic obstetric ultrasonography.

Clinical supervisors assess students according to 5 proposed levels of student entrustment decision-making, which are graded as follows: 1, not allowed to practice EPAs (but may or may not be permitted to observe); 2, may practice or act under ongoing full supervision (which may be as a coactivity or with supervisor observing in the room); 3 , may act under reactive supervision (the supervisor is available either on site, to double check all or some data, or at a distance); 4, may act unsupervised; and 5, is permitted to supervise others in the practice of EPAs. ${ }^{16}$ Another model involving dichotomous trust judgments ("pre-entrustable learner" and "entrusted learner") has been adopted by the Association of American Medical Colleges for students entering residency. ${ }^{17}$ Coupled with milestone markers (progressive points in the workplace-based learning trajectory by which time the learner is expected to demonstrate specific outcomes) EPAs promote a safe and gradual transition from supervised tasks to justified autonomous responsibilities, a critical element for ultimate readiness to practice (Table 1$).{ }^{18}$

\section{EPAS FOR PHARMACY EDUCATION}

Adoption of EPAs for postgraduate medical education programs has extended from Europe to North America and other continents, as well as to other professions (veterinary medicine, nursing). Recently, the Academic Committee of the American Association of Colleges of Pharmacy (AACP) embarked upon the identification of EPAs for PharmD graduates. With reference to educational outcome statements of the Accreditation Council for Pharmacy Education, initial EPAs have been written for roles as patient care provider, interprofessional team member, population health care provider, practice manager, information master, and selfdeveloper. ${ }^{19}$ In March 2016, draft EPA task statements were distributed to AACP stakeholders for consultation with regard to their description, the conditions under which the intended activities would be performed, and the level of independent performance expected by graduation. Examples of the draft EPAs include administering and documenting adult vaccination (as recommended by the Centers for Disease Control and Prevention) and answering a drug information request from a health care professional or patient. ${ }^{20}$ This enterprise follows first experiences in EPA development for advanced pharmacy practice experiences (APPEs) that were independently initiated at the University of Minnesota. ${ }^{21}$ The university's College of Pharmacy created EPAs linked to specific trust-level expectations following years 1, 2, and 3 of its APPEs and piloted these EPAs in summer 2016.22 Programs making efforts to adopt EPAs are encouraged to continue sharing their implementation experiences as proof of concept and to further inform practical aspects associated with the application of EPAs to pharmacy. ${ }^{20}$

What does the development and adoption of EPAs mean for pharmacy education in Canada? The scope of pharmacy practice in Canada and the United States is closely aligned, and so too are the 2 countries' pharmacy curricula. ${ }^{23}$ The Center for the Advancement of Pharmacy Education (CAPE) ${ }^{24}$ describes 15 educational outcomes for graduates of US pharmacy programs, including caregiver, manager, communicator, collaborator, and advocate, which are also found in the AFPC educational outcomes for Canada. ${ }^{6}$ Notably, Canadian faculties of pharmacy are transitioning to the PharmD as an entry-topractice degree, a form of credentialing that has been in place in the United States for the past 20 years. It is conceivable, then, that in parallel with entry-to-practice PharmD curricular reform, Canadian pharmacy programs would also consider adopting EPAs for pharmacy students at graduation. Although pharmacy programs across the provinces share educational outcomes and accreditation standards, workplace-based assessment practices are not necessarily homogeneous. Clerkship evaluation forms may share similar elements, but may vary in format, length, and specific response options. Implementing EPAs would imply greater uniformity in workplace-based assessment processes through application of the 5 levels of entrustment decision-making.

\section{Table 1. Hypothetical Expected Entrustment Levels for 5 Program EPAs as Student Milestones at Various Points across an Experiential Training Curriculum of 10 Consecutive Clerkships ${ }^{18}$}

\begin{tabular}{|c|c|c|c|c|c|c|c|c|c|c|}
\hline \multirow{2}{*}{$\begin{array}{l}\text { Entrustable } \\
\text { Professional Activity }\end{array}$} & \multicolumn{10}{|c|}{ Clerkship; Entrustment Level* } \\
\hline & IPPE & IPPE & IPPE & IPPE & IPPE & IPPE & APPE & APPE & APPE & APPE \\
\hline & 1 & 2 & 3 & 3 & 3 & 4 & 4 & 4 & 5 & 5 \\
\hline EPA B & NA & NA & 1 & 1 & 2 & 2 & 3 & 3 & 4 & 4 \\
\hline EPAC & 1 & 1 & 2 & 2 & 3 & 3 & 4 & 4 & 5 & 5 \\
\hline EPA D & 1 & 2 & 3 & 3 & 3 & 4 & 4 & 5 & 5 & 5 \\
\hline EPA E & NA & 1 & 2 & 2 & 3 & 3 & 4 & 4 & 4 & 5 \\
\hline
\end{tabular}




\section{LESSONS LEARNED}

In the decade since EPAs were first proposed by ten Cate and Scheele, ${ }^{13}$ much has been learned about their systematic development and implementation. Health professional programs considering clinical supervisor trust-decisions as an assessment construct in experiential training benefit from guiding principles gained from others' experience. ${ }^{18}$ Wide stakeholder engagement to scope activities considered essential to pharmacy may involve program directors, educators, researchers, regulatory authorities, and especially practitioners from varied care settings who will be expected to practically apply EPAs in future student supervisory experiences. EPAs identified for a particular setting or program must be well described to ensure shared understanding by multiple users. A fully elaborated EPA includes the required experience, knowledge, skills, attitudes, and behaviour; the specification and limitations distinguishing its unique scope; and information pertaining to assessment and the level of supervision to be reached at each stage of training; in addition, an expiration date may be prescribed. ${ }^{25}$ Ensuring that EPAs reflect the professional activities that students are expected to perform autonomously by graduation may be done through comparison with existing documents, namely the AFPC educational outcomes. ${ }^{6}$ For example, grids illustrating relations between an existing framework of competencies and described EPAs ("matrix mapping") have been generated within American College of Graduate Medical Education programs for residents completing subspecialties such as family or emergency medicine, pulmonary and critical care, and obstetrics and gynecology and by the Association of American Medical Colleges for its aforementioned core EPAs. The AACP has similarly outlined potential linkages between its recently devised core EPAs and the CAPE educational outcome domains (Table 2). ${ }^{20}$ Determining these networks requires that the EPAs in question are comprehensive and constitute all activities expected of health professionals transitioning out of training and into day 1 of practice. ${ }^{25,26}$

Currently, the 7 AFPC educational outcomes are elaborated by 20 statements and 70 explanations (recently streamlined from the 34 statements and 170 explanations in the previous version, published in 2010). Although the breadth of identified EPAs should portray a discipline's end-of-training requirements, long lists of detailed activities would simply compound the drawbacks already associated with competencies. ${ }^{27}$ For

Table 2. Sample Mapping of AACP Proposed EPAs for New Pharmacy Graduates with 2013 CAPE Educational Outcomes

EPA Core Statement*

CAPE Domainst and Subdomains

\begin{tabular}{|c|c|c|c|c|c|c|c|c|c|c|c|c|c|c|}
\hline 1 & \multicolumn{4}{|c|}{2} & \multicolumn{6}{|c|}{3} & \multicolumn{4}{|c|}{4} \\
\hline & 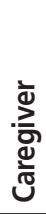 & $\begin{array}{l}\frac{\bar{d}}{0} \\
\frac{\pi}{\pi} \\
\frac{\pi}{\Sigma}\end{array}$ & $\begin{array}{l}\text { 흘 } \\
\text { 을 } \\
\text { 옴 }\end{array}$ & $\frac{\text { d̄ }}{\frac{0}{2}}$ & 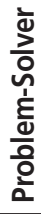 & $\begin{array}{l}\text { 흠 } \\
\text { ț } \\
\text { 움 }\end{array}$ & 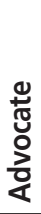 & $\begin{array}{l}\frac{1}{0} \\
\frac{0}{0} \\
\text { 응 } \\
\frac{0}{\overline{0}} \\
\overline{0}\end{array}$ & $\frac{\text { d }}{\frac{0}{\partial}}$ & 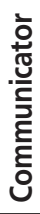 & 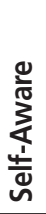 & 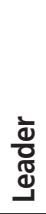 & $\begin{array}{l}\text { 호 } \\
\text { to } \\
\text { o } \\
\text { 드 }\end{array}$ & 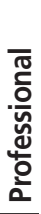 \\
\hline & $x$ & $x$ & $X$ & & $X$ & & & & $X$ & $X$ & & & & \\
\hline$X$ & $X$ & & & & $X$ & & & & & $X$ & & & & \\
\hline$X$ & $X$ & $X$ & & & & & $x$ & & $X$ & & & & & \\
\hline & $x$ & $X$ & & & $x$ & $X$ & & $X$ & & $x$ & & & & \\
\hline & $x$ & $X$ & & & & & & $x$ & & $x$ & & & & \\
\hline
\end{tabular}

AACP EPA domain:

Patient care provider

Collect information to identify a

patient's medication-related programs and health-related needs

Analyze information to determine the effects of medication therapy, identify medication-related problems, and prioritize health-related needs

Establish patient-centred goals and create an evidence-based and cost-effective care-plan for the patient in collaboration with the patient, caregivers, and other health professionals

Implement a care plan in collaboration with the patient, caregivers, and other health professionals

Follow up and monitor a care plan

AACP $=$ American Association of Colleges of Pharmacy, CAPE = Center for the Advancement of Pharmacy Education

EPA = entrustable professional activity.

${ }^{*}$ Core statements for patient care provider domain as listed by Haines and others. ${ }^{20}$

tCAPE domains: 1 = foundational knowledge, 2 = essentials for practice and care, 3 = approach to patient and care,

$4=$ personal and professional development. 
associated reasons, less than 30 EPAs for a program has been recommended, although the number of EPAs for undergraduate medical education and various graduate subspecialty residencies ranges from 4 to $75 .{ }^{18}$ Additionally, certain desirable trainee attributes do not meet the definition of an EPA as a unit of work and would pose problems for assessment. For example, although a commitment to lifelong learning and demonstration of professional behaviour are important educational outcomes, they are not suitable as an entrustment decision because they are not discrete tasks associated with patient care. ${ }^{18,28,29}$

\section{What Would Adoption of EPAs Mean for Pharmacy Students?}

Couching a preceptor's performance feedback as decisions of trust ("I don't think you are ready yet to discharge or counsel patients alone") loosens the ties of student capabilities to peergroup performance (rated as deviations around the "average") and may mitigate leniency bias and the associated inability to discriminate between students. ${ }^{30}$ Similarly, students could use entrustment levels to self-assess and communicate with clinical supervisors their own comfort in the level of independent care. ${ }^{31}$ Using EPAs as a vehicle to determine attainment of desired educational outcomes could then refocus experiential training on a student's unique trajectory. ${ }^{25}$ According to the proposed levels of entrustment decision-making previously described, pharmacy students would expect to reach level 4 ("may act unsupervised") by graduation, while recognizing that different students may achieve such levels for certain EPAs earlier in their continuums of learning. ${ }^{16}$ Indeed, a fundamental principle of the EPA framework is that an individual's progress is not bound by a fixed time, but instead proceeds according to demonstrated competencies (ideally observed on multiple occasions). ${ }^{25,32,33}$ Yet, as an additional component of the competency-EPA matrix, milestones can also be mapped in a way to identify a "minimal threshold" of what would be expected behaviours at different points of training. In this way, clinical supervisors and students understand explicitly the ultimate trajectory that is expected. When EPAs are documented in learning portfolios, students (and programs) can track progress in terms of EPAs attained throughout multiple clerkships to identify needs for learner support. ${ }^{18,25}$

\section{What Would Adoption of EPAs Mean for Patients?}

In the face of ongoing morbidity and mortality associated with preventable medical error in health care systems, patient safety principles are being increasingly emphasized in curricula for pharmacy and other health professions. ${ }^{34}$ Although clinical supervisors ought to challenge students beyond their comfort zones to promote learning and to facilitate progression to independent care provision, the US Institute of Medicine and others have highlighted the importance of adequate trainee supervision to ensure quality care. ${ }^{35,36}$ EPAs serve as a framework for workplace-based assessment that is explicit in assigning preceptor judgments of trust in student capabilities to perform specific aspects of patient care. Students generally start as novice or apprentice care providers with limited independent responsibilities and will progress through stages of reduced supervisorsupported care activities, thereby minimizing the risk for patients. ${ }^{37,38}$

\section{What Would Adoption of EPAs Mean for Canadian Hospital Pharmacists?}

As in any educational initiative, particularly those involving curricular components of workplace-based training, development and sustained support of adjunct faculty are essential, but practical experiences in this regard are still emerging. ${ }^{24,39}$ The ways in which pharmacy preceptors form or articulate trust judgments has not been well studied, and hospital pharmacists are therefore encouraged to participate in EPA identification processes, as well as any future feasibility and pilot studies. ${ }^{40} \mathrm{In}$ at least one surgical training program, a proposed supervisor EPA rating scale was aligned with trust levels from 1, "I had to do it" (i.e. the student did not do the activity, was not given the opportunity to do it, or required hands-on guidance), to level 5, "I did not need to be there" (i.e. the student had complete independence, understood and performed the activity safely, and is practice-ready). ${ }^{30}$ Although EPAs are intended to promote an intuitive student evaluation process, direct observation and feedback by clinical supervisors remains requisite in grounding their trust decisions with sufficient data. ${ }^{12}$ However, under this workplace-based assessment model, practical preceptor challenges for balancing teaching demands and service expectations will persist. ${ }^{41}$ As pharmacy degrees continue to transition in Canada, hospital pharmacists will also have to manage expectations of trust for different levels of trainees (entry-to-practice PharmD students, postgraduate residents, pharmacists as PharmD students). Like the postgraduate specialties in medicine, Canadian postgraduate year 1 and year 2 pharmacy residency programs may devise and map more specialized activities while retaining the same levels of trust judgments. ${ }^{36}$

\section{CONCLUSION}

Canadian pharmacy education is transitioning from baccalaureate to doctorate as the entry-to-practice credential, which marks an ideal time for its programs to purposively re-evaluate the profession's competency framework and to augment workplace-based assessment with expressed pedagogies in mind. If the EPA approach is pursued, processes in the development and adoption of EPAs will require enlistment 
of clinical supervisors, including preceptors in hospitals and associated care settings, who will additionally use new benchmarks to relate their judgments of expected pharmacy student behaviour for undergraduates. Indeed, the high levels of patients' faith in pharmacist knowledge and expertise are matched by the trust that pharmacy programs continue to place in the preceptors who are guiding students toward safe and independent practice.

\section{References}

1. Ipsos Reid and Reader's Digest release annual Trusted Brand ${ }^{\mathrm{TM}}$ survey: Canadians continue to remain loyal to brands they trust most [news release]. Ottawa (ON): Ipsos Reid; 2015 Jan 19 [cited 2017 Nov 21]. Available from: https://www.ipsos.com/sites/default/files/publication/2015-01/6731 rev1.pdf

2. Norman J. Americans rate healthcare providers high on honesty, ethics. Washington (DC): Gallop News Inc; 2016 Dec 19 [cited 2017 Nov 21]. Available from: http://news.gallup.com/poll/200057/americans-rate-healthcare-providers-high-honesty-ethics.aspx

3. Public trust in the professions. London (UK): VetFutures Research Group; 2015 [cited 2017 Nov 21]. Available from: https://www.vetfutures.org.uk/ resource/public-trust-in-the-professions-may-2015/

4. Roy Morgan image of professions survey 2017: health professionals continue domination with nurses most highly regarded again; followed by doctors and pharmacists. Melbourne (Australia): Roy Morgan Research; 2017 [cited 2017 Nov 21]. Available from: www.roymorgan.com/findings/7244-roy-morganimage-of-professions-may-2017-201706051543

5. Coletto D. Pharmacists in Canada: a national survey of Canadians on their perceptions and attitudes towards pharmacists in Canada. Ottawa $(\mathrm{ON})$ : Abacus Data; 2015 Feb.

6. AFPC educational outcomes for first professional degree programs in pharmacy in Canada 2017. Ottawa (ON): Association of Faculties of Pharmacy of Canada; 2017.

7. Accreditation standards for the first professional degree in pharmacy programs. Toronto (ON): Canadian Council of Accreditation for Pharmacy Programs; 2013 Jan [revised $2014 \mathrm{Jul}$.

8. Lyons K, McLaughlin JE, Khanova J, Roth MT. Cognitive apprenticeship in health sciences education: a qualitative review. Adv Health Sci Educ. 2017; 22(3):723-39.

9. Ginsburg S, McIlroy J, Oulanova O, Eva K, Regehr G. Toward authentic clinical evaluation: pitfalls in the pursuit of competency. Acad Med. 2010; 85(5):780-6.

10. Bogo M, Regehr C, Woodford M, Hughes J, Power R, Regehr G. Beyond competencies: field instructors' descriptions of student performance. J Soc Work Educ. 2006;42(3):579-93.

11. Wilbur K, Hassaballa N, Mahmood OS, Black EK. Describing student performance: a comparison among clinical preceptors across cultural contexts. Med Educ. 2017;51(4):411-22.

12. Driessen $\mathrm{E}$, Scheele $\mathrm{F}$. What is wrong with assessment in postgraduate training? Lessons from clinical practice and educational research. Med Teach. 2013; 35(7):569-74.

13. ten Cate O, Scheele F. Viewpoint: Competency-based postgraduate training: can we bridge the gap between theory and clinical practice? Acad Med. 2007; 82(6):542-7.

14. ten Cate O. Nuts and bolts of entrustable professional activities. J Grad Med Educ. 2013;5(1):157-8
15. Scheele F, Caccia N, van Luijk S, den Rooyen C, van Loon K, editors. Better education for obstetrics and gynecology (BOEG). Dutch national competency based curriclum for obstetics \& gynecology (NL). Utrecht (Netherlands): Nederlands Vereniging voor Obstetrie; 2013.

16. Chen HC, van den Broek WES, ten Cate O. The case for use of entrustable professional activities in undergraduate medical education. Acad Med. 2015; 90(4):431-6.

17. Core entrustable professional activities for entering residency: curriculum developer's guide. Washington (DC): Association of American Medical Colleges; 2014.

18. ten Cate O, Chen HC, Hoff RG, Peters H, Bok H, van der Schaaf M. Curriculum development for the workplace using entrustable professional activities (EPAs): AMEE guide no. 99. Med Teach. 2015;37(11):983-1002.

19. Accreditation standards and key elements for the professional program in pharmacy leading to the doctor of pharmacy degree. Chicago (IL): Accreditation Council for Pharmacy Education; 2015.

20. Haines ST, Pittenger AL, Stolte SK, Plaza CM, Gleason BL, Kantorovich A, et al. Core entrustable professional activities for new pharmacy graduates. $\mathrm{Am}$ J Pharm Educ. 2017;81(1): Article S2.

21. Pittenger AL, Chapman SA, Frail CK, Moon JY, Undeberg MR, Orzoff JH. Entrustable professional activities for pharmacy practice. Am J Pharm Educ. 2016;80(4): Article 57

22. Pittenger AL. Three schools' experiences with using EPAs in assessment of pharmacy students [presentation]. American Association of Colleges of Pharmacy Annual Meeting; 2016 Jul 23-27; Anaheim (CA).

23. Kehrer JP, Schindel TJ, Mann HJ. Cooperation in pharmacy education in Canada and the United States. Am J Pharm Educ. 2010;74(8): Article 142.

24. Medina MS, Plaza CM, Stowe CD, Robinson ET, DeLander G, Beck DE, et al. Center for the Advancement of Pharmacy Education 2013 educational outcomes. Am J Pharm Educ. 2013;77(8): Article 162.

25. ten Cate O, Snell L, Carraccio C. Medical competence: the interplay between individual ability and the health care environment. Med Teach. 2010;32(8): 669-75.

26. Caverzagie KJ, Cooney TG, Hemmer PA, Berkowitz L. The development of entrustable professional activities for internal medicine residency training: a report from the Education Redesign Committee of the Alliance for Academic Internal Medicine. Acad Med. 2015;90(4):479-84.

27. Touchie $\mathrm{C}$, ten Cate $\mathrm{O}$. The promise, perils, problems and progress of competency-based medical education. Med Educ. 2016;50(1):93-100.

28. Lockyer J, Bursey F, Richardson D, Frank JR, Snell L, Campbell C, et al. Competency-based medical education and continuing professional development: a conceptualization for change. Med Teach. 2017;39(6):617-22.

29. Tekian A. Are all EPAs really EPAs? Med Teach. 2017;39(3):232-3.

30. Rekman J, Gofton W, Dudek N, Gofton T, Hamstra SJ. Entrustability scales: outlining their usefulness for competency-based clinical assessment. Acad Med. 2016;91(2):186-90.

31. Sklar DP. Trust is a two-way street. Acad Med. 2016;91(2):155-8.

32. Frank JR, Snell LS, ten Cate O, Holmboe ES, Carraccio C, Swing SR, et al. Competency-based medical education: theory to practice. Med Teach. 2010;32(8):638-45.

33. Govaerts M, van der Vleuten CPM. Validity in work-based assessment: expanding our horizons. Med Educ. 2013;47(12):1164-74.

34. Multi-professional patient safety curriculum guide. Geneva (Switzerland): World Health Organization; 2011.

35. Chaiklin $S$. The zone of proximal development in Vygotsky's analysis of learning and instruction. In: Kozulin A, Gindis B, Ageyev VS, Miller SM, editors. Vygotsky's educational theory in cultural context. Cambridge (UK): Cambridge University Press; 2003. p. 39-64.

36. Committee on the Future Health Care Workforce for Older Americans (Rowe JW, chair). Retooling for an aging America: building the health care workforce. Washington (DC): National Academies Press; 2008.

37. Kogan JR, Conforti LN, Iobst WF, Holmboe ES. Reconceptualizing variable rater assessments as both an educational and clinical care problem. Acad Med. 2014;89(5):721-7. 
38. Carraccio C, Englander R, Holmboe ES, Kogan JR. Driving care quality: aligning trainee assessment and supervision through practical application of entrustable professional activities, competencies, and milestones. Acad Med. 2016;91(2):199-203

39. van Loon KA, Driessen EW, Teunissen PW, Scheele F. Experiences with EPAs, potential benefits and pitfalls. Med Teach. 2014;36(8):698-702.

40. Hauer KE, Soni K, Cornett P, Kohlwes J, Hollander H, Ranji SR, et al. Developing entrustable professional activities as the basis for assessment of competence in an internal medicine residency: a feasibility study. J Gen Intern Med. 2013;28(8):1110-4.

41. Watling C, LaDonna KA, Lingard L, Voyer S, Hatala R. 'Sometimes the work just needs to be done': socio-cultural influences on direct observation in medical training. Med Educ. 2016;50(10):1054-64.

Kerry Wilbur, BSCPharm, ACPR, PharmD, MSCPH, FCSHP, is an Associate Professor and Executive Director of Entry-to-Practice Education with the Faculty of Pharmaceutical Sciences at The University of British Columbia, Vancouver Campus, Vancouver, British Columbia.
Competing interests: None declared.

\section{Address correspondence to:}

Dr Kerry Wilbur

Faculty of Pharmaceutical Sciences

The University of British Columbia

3511-2405 Wesbrook Mall

Vancouver BC V6T 1 Z3

e-mail: kerry.wilbur@ubc.ca

\section{Funding: None received.}

Acknowledgements: The author wishes to thank Dr Fedde Scheele, EPA pioneer and Professor in Obstetrics and Gynaecology at the University Medical Centre of Vrije Universiteit in Amsterdam, and Dr Erik Driessen, Professor and Chair of the Department of Educational Development and Research, School of Health Professions Education, Faculty of Health, Medicine, and Life Sciences at Maastricht University in Maastricht, the Netherlands, for their critical pre-submission review of this paper.

\section{BEST..is better}

\section{One resource for all types of compounding by pharmacies}

\section{WHAT'S INSIDE?}

- Information for pharmacists, pharmacy technicians, planners, architects, engineers-and others who are involved in decisions or activities that affect compounding

- Guidelines for aseptic compounding, non-aseptic compounding, and compounding which involves hazardous drugs-including radiopharmaceuticals

- Best and leading guidelines on topics such as training, planning and designing the physical environment, developing an air quality strategy, cleaning and decontaminating areas, monitoring the environment, garbing and hand hygiene, developing compounding procedures, documenting, and much more-all in only 230 pages

\section{Learn what best looks like: add this publication to your library!}

HAVE A SNEAK PEEK OR ORDER AT:

https://cshp.ca/compounding-guidelines-pharmacies CSHP MEMBERS PAY A DISCOUNTED PRICE
Canadian Society of Hospital Pharmacists

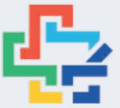

Société canadienne des pharmaciens d'hôpitaux 